\title{
Experience with Ambulatory Management of Pleural Pathologies Utilizing Small-Bore Indwelling Pleural Catheters
}

\author{
Imad-ud-din Saqib $^{1}$, Mobeen Iqbal ${ }^{2}$, Atif Rana ${ }^{3}$, Saira Hassan ${ }^{4}$
}

1. Department of Plastic Surgery, Shifa International Hospital, Islamabad, Pakistan 2. Department of Pulmonology \& Critical Care, Shifa International Hospital, Islamabad, Pakistan 3. Department of Interventional Radiology, Shifa International Hospital, Islamabad, Pakistan 4. Hematology/oncology, Shifa International Hospital, Islamabad, Pakistan

$\square$ Corresponding author: Imad-ud-din Saqib, imaduddinsaqib@gmail.com

Disclosures can be found in Additional Information at the end of the article

\section{Abstract}

\section{Introduction}

Pleural effusion is the excess fluid that accumulates in the pleural space. Pneumothorax is the collection of free air in the pleural cavity, while empyema is the collection of pus in the pleural cavity. Such pleural pathologies pose a great challenge to patients and health care professionals alike. While multiple management options exist, the major portion of it is carried out in the inpatient setting. We sought to evaluate the ambulatory use of indwelling pleural catheters for pleural pathologies, including malignant pleural effusion, empyema, and primary spontaneous pneumothorax.

\section{Methods}

We conducted a prospective case series analysis of 15 patients with various pleural pathologies in which an indwelling pleural catheter was placed by interventional radiologists on an outpatient basis and subsequently followed-up in a pulmonary clinic. Results were analyzed on the basis of clinical, as well as radiological progress with parameters being complete, partial, or no resolution. We also obtained prospective data on the quality of life of these patients.

\section{Results}

Six out of seven patients with malignant pleural effusion reported clinical (complete or partial) resolution, while three reported radiological (complete or partial) resolution. Two of the three patients with nonmalignant pleural effusions reported complete clinical as well as radiological resolution. All three patients with empyema reported complete clinical resolution and partial radiological resolution, while both patients with primary spontaneous pneumothorax reported complete clinical and radiological resolution. Patients reported preserved or improved quality of life with the whole process managed on an outpatient basis.

\section{Conclusion}

We report a high rate of clinical and radiological resolution in various pleural pathologies in our study, which is first of its kind from this part of the world. It demonstrates the feasibility of ambulatory management of pleural pathologies with a multidisciplinary approach. 
Categories: Radiology, Oncology, Pulmonology

Keywords: empyema, pleural disease, palliative care, systemic disease and lungs, malignancies, pneumothorax

\section{Introduction}

Pleural pathologies are common in pulmonary practice. Malignant pleural effusions and pneumothoraces make up a significant number of patient visits to hospitals and hospital admissions worldwide [1].

The management of pleural effusion depends on the underlying etiology. Various management techniques have been reported and suggested by the recent, evidence-based, British Thoracic Society (BTS) guidelines. The options are broadly categorized as diagnostic and therapeutic in nature. Traditionally, effusions and pneumothoraces are aspirated by needle or drained through large bore chest tubes. Recurrent malignant effusions may require the instillation of a sclerosant, thoracic surgery (open or video-assisted), or placement of an indwelling pleural catheter. Similarly, ambulatory drainage with Heimlich valve, open thoracotomy with pleurectomy, video-assisted thoracoscopic surgery (VATS) with pleurectomy, pleural abrasion, and surgical chemical pleurodesis are used in cases of pneumothorax [2].

With the advent of small-bore catheters, better known as indwelling pleural catheters (IPC), management of pleural pathologies have changed significantly. IPCs are increasingly being used and multiple studies have shown no significant differences between the outcomes of large and small-bore chest tubes [3-5]. Many centers worldwide are now considering IPC as the firstline treatment in place of large-bore intercostal drains, with or without chemical pleurodesis for the management of pleural pathologies [6-7], and trials are underway to evaluate their efficacy, cost effectiveness, hospital stay, and quality of life [8-9].

IPCs are also being used in the management of tuberculous, parapneumonic, empyema, and transudative causes of pleural effusions [10].

In Pakistan, large-bore chest tubes are still the most frequently used intervention for drainage of pleural effusions and pneumothoraces with chemical or surgical pleurodesis [11-12]. IPC use is becoming popular in some of the tertiary care centers due to its ease and patient comfort.

Recent studies have described the use of IPC on an outpatient basis followed by subsequent outpatient follow-up in order to further decrease the length of hospital stay [13-15]. Our aim in this study is to describe our experience with outpatient insertion and management of IPCs, pleurodesis, the utilization of IPC, when required, and its effectiveness in relief of symptoms, patient ease, length of hospital stay, cost, and prognosis, along with any complications arising from it.

\section{Materials And Methods \\ Patients and study design}

We conducted a retrospective case series analysis from January 2015 to December 2016. All patients who had an IPC placed in the outpatient setting and remained in outpatient follow-up were included in the study. The data of the selected patients were collected from medical records. Patients with incomplete records or lost to follow-up were excluded from the study. An informed consent about the use of patient-related data was obtained prospectively from patients, and in cases where the patients were unable to give consent, consent was obtained from their relatives. The study was approved by the institutional review board of Shifa International Hospital, Islamabad, Pakistan. 


\section{Cureus}

\section{Patient management}

The patients were managed using a multidisciplinary approach involving physicians from the pulmonology, interventional radiology, and oncology divisions if required. The decision to insert the indwelling pleural catheter was based on the judgment of the pulmonologist. Patients were subsequently referred to the interventional radiologist for assessment and a final decision.

Before proceeding with the procedure, patients were required to have their complete blood count, prothrombin time, INR (international normalized ratio), and chest X-ray done. Every patient was told about the procedure, along with possible complications, and given an informed consent form to be signed by the patient or the next of kin according to hospital policy.

All patients undergoing IPC had same-day imaging prior to IPC insertion. Before the start of the procedure, patients' vitals, including temperature, blood pressure, and pulse, were observed for a few minutes to ensure clinical stability.

The patient was positioned in a sterile environment and landmarks were identified. For pneumothorax, the fourth or fifth intercostal space on the anterior axillary line was identified. In the case of pleural effusion or empyema, ultrasonography was used to identify free floating effusions or largest loculation and the landmark was decided on accordingly. The skin was anesthetized with $10 \mathrm{~mL}$ of $2 \%$ lidocaine. An 8-French or 10-French straight drain with multiple side-holes (Easydrain ${ }^{\circledR}$, Vygon Co, Ecouen, France) or size 8-French to 12-French pigtail catheter was used according to the type of pleural pathology.

For the straight drain, a preloaded 12-gauge needle was used to puncture the site under ultrasound guidance. Once in the pleural space, the catheter was fed through the needle and the needle eventually removed. The amount of air aspirated was measured. In case of pigtail catheter, under fluoroscopic and or ultrasound guidance, an 18-gauge needle was used to puncture the selected site. The amount of fluid aspirated was measured; color was noted and sent for routine analysis along with any other test that aided in the confirmation of the suspected diagnosis, if not available before. A guidewire that was passed through the needle and the pigtail catheter was then inserted. The guidewire was removed once the catheter was in place. Figure 1 shows radiographs of patients after the insertion of the catheter.

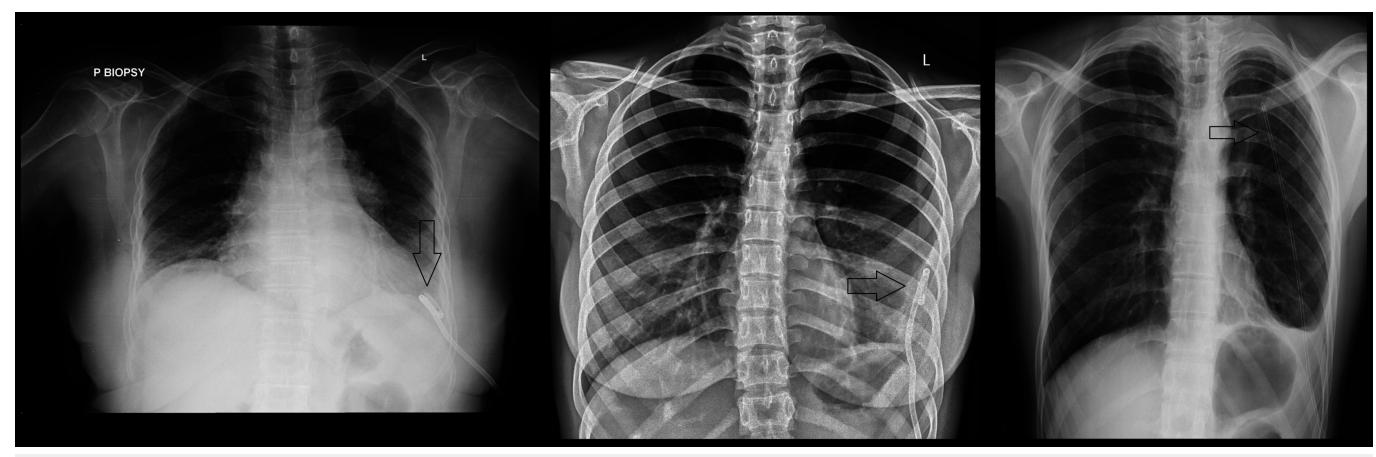

FIGURE 1: The figure shows the catheter in place in a patient with malignant pleural effusion (left), empyema (center) and primary spontaneous pneumothorax (right)

The catheter was sutured to the skin using silk. A Heimlich valve, in the case of a pneumothorax, or a drainage bag, in the case of a pleural effusion or empyema, was attached to 
end of the catheter. A post-procedure chest X-ray was done to ensure correct positioning of the IPC, to rule out any procedural complication, and to compare the change/resolution of the radiological appearance of pleural pathology with pre-procedural chest X-ray.

The patients' vital signs were again monitored for a few minutes to ensure stability. The patient and his or her relatives were counseled regarding care of the IPC and the attached Heimlich valve or drainage bag. The patient was subsequently referred to the pulmonary clinic for final instructions regarding maintaining a daily record of fluid drainage or any other queries about home management before leaving the hospital. They were advised to follow-up for subsequent decisions regarding drain removal and other interventions like chemical pleurodesis in the pulmonary clinic.

Any complications encountered by the patient or observed by the pulmonologist in follow-up visits were noted and managed in conjunction with interventional radiology or oncology if required.

Pleurodesis was performed in the pulmonary clinic when daily fluid output was less than $100 \mathrm{cc}$ (cubic centimeters) on three consecutive days with no or minimal residual effusion on chest Xray in case of recurrent malignant effusions or complete lung expansion in case of pneumothorax with minimal or no air leak. We used sterilized 3 to 5 grams talc slurry instilled in the pulmonary clinic under aseptic conditions. In order to minimize pain, the talc slurry was mixed with $10-20 \mathrm{cc}$ of $2 \%$ lignocaine. Subsequent pain was managed with oral paracetamol and tramadol when required. In case of pneumothorax, the IPC was removed the same day after instillation of talc with a follow-up chest X-ray, while patients with malignant effusions were asked to report back after two days for IPC removal and follow-up chest X-ray.

Data on quality of life were obtained retrospectively by asking patients, or their close relatives in case the patient had died, in a telephonic interview. They were asked regarding the activities they were able to perform with the catheter in place and for any limitations of their usual daily life activities.

\section{Operational definitions}

On follow-up, patients were assessed both clinically as well as radiologically. 'Complete clinical resolution' was labeled when the patient's symptoms, i.e. shortness of breath and fever, were resolved and fluid drainage had decreased to $100 \mathrm{cc}$ or less in 24 hours. In case of absence of any of these criteria, 'partial resolution' was labeled. If there was no improvement in symptoms, 'no resolution' was labeled.

'Complete radiological resolution' was labeled when the patient's radiographs returned to normal. If radiographs still showed some signs of the pathology, but there was a significant improvement in the gross appearance of the radiographs, the label of 'partial radiological resolution' was used. If there was no improvement or worsening of the radiological appearance, the patient was labeled as having 'no radiological resolution'.

In patients in whom partial or complete clinical resolution had occurred, recurrence was considered when the patients developed the same symptoms, shortness of breath with or without fever, accompanied with worsening of the radiological appearance when compared with the radiographs at the time when the disease process was labeled as having been clinically resolved.

Success was defined as clinical resolution, either complete or partial, regardless of the radiological outcome. 


\section{Cureus}

\section{Statistical analyses}

The data collected were entered and analyzed using IBM's Statistical Package for Social Sciences (SPSS) (IBM Corp., Armonk, NY), version 24. Patient identifiers were removed once all the data had been entered and thoroughly reviewed to rule out any mistakes in the data entry process. Descriptive statistics were used to present the patient characteristics, any comorbidities, pulmonary and pleural pathologies, catheter size and its type, days to catheter removal, clinical and radiological resolution, any complications, and the need for alternative management. Continuous data are reported with the mean and standard deviations where required.

\section{Results}

A total of 27 patients were enrolled between January 1, 2015 through December 31, 2016 who underwent IPC insertion on an outpatient or ambulatory basis. Twelve patients were excluded due to reasons mentioned in Figure 2; thus, 15 patients qualified for our study.

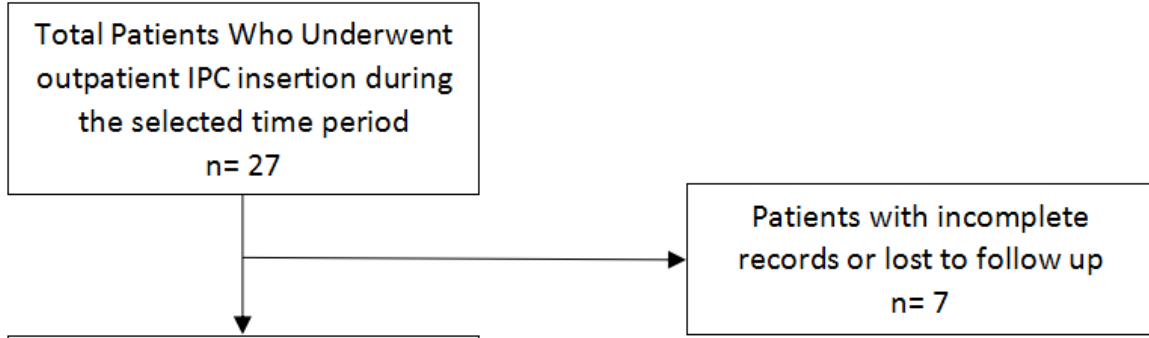

Patients Who Underwent outpatient IPC insertion with complete records $n=20$

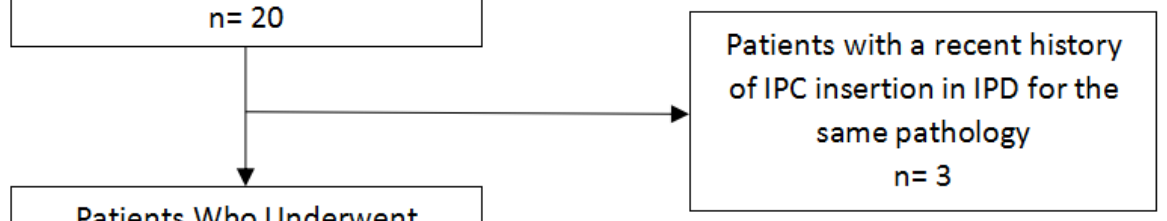

Patients Who Underwent outpatient IPC insertion $n=17$

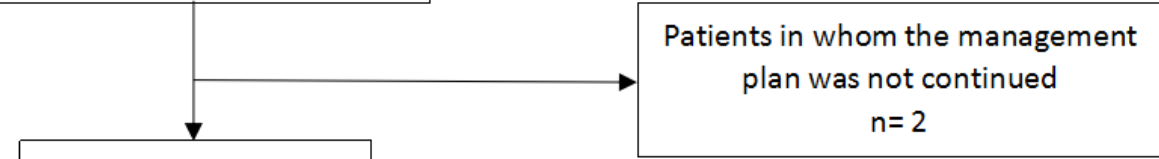

Patients Who

Qualified for the Study $n=15$

\section{FIGURE 2: Outline of the patient selection criteria for the study}

IPD = inpatient department, IPC = indwelling plueral catheter

All patients were South Asian in origin with a mean age of $55.2 \pm 16.3$ years. There were seven (46.7\%) males and eight (53.3\%) females. Seven (46.7\%) patients were diagnosed with malignant pleural effusion. The details about various causes of pleural effusions, other pleural pathologies, comorbidities, days to the removal of the catheter, and size and type of catheter 


\section{Cureus}

inserted are mentioned in Table 1.

Malignant Pleural Effusions

Age
(yrs) Sex Diagnosis

$170 \quad$ F $\quad$ Breast Carcinoma

240

F Breast Carcinoma

$3 \quad 69$

F Ovarian Carcinoma

456

F

Pleomorphic Sarcoma (Chest Wall)

$\begin{array}{llll}5 & 80 & \text { M } & \text { Leiomyosarcoma }\end{array}$

$6 \quad 60$ F $\quad$ Pulmonary Adenocarcinoma

$7 \quad 55$

F Mesothelioma

Non-malignant Pleural Effusions

Age Sex Comorbidities

(yrs)

F DM, HTN, CKD

$8 \quad 68$

$$
\text { F DM, HTN, CKD }
$$

$9 \quad 68 \quad M \quad$ CKD

$\begin{array}{lll}10 & 61 & M\end{array} \quad$ Limbic Vasculitis

Empyema

Age
(yrs) Sex Comorbidities

$1156 \quad M \quad$ None

1258

M None

13

25 F None

Primary Spontaneous Pneumothorax
Comorbidities

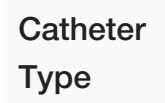

Catheter

Days to

Size

Removal

None

Pigtail

catheter

$8 \mathrm{Fr}$

28

Pigtail

None

catheter

$8 \mathrm{Fr}$

10

None

Pigtail

catheter

$12 \mathrm{Fr}$

DM, HTN

Pigtail

catheter

$12 \mathrm{Fr}$

8

Pigtail

catheter

$12 \mathrm{Fr}$

11

Straight drain $10 \mathrm{Fr}$

46

Pigtail

catheter

$12 \mathrm{Fr}$

11

None

$\begin{array}{lll}\begin{array}{l}\text { Catheter } \\ \text { Type }\end{array} & \begin{array}{l}\text { Catheter } \\ \text { Size }\end{array} & \begin{array}{l}\text { Days to } \\ \text { Removal }\end{array} \\ \begin{array}{l}\text { Straight drain } \\ \text { Pigtail }\end{array} & 30 \mathrm{Fr} & 30 \\ \begin{array}{l}\text { catheter } \\ \text { Pigtail }\end{array} & 8 \mathrm{Fr} & 10 \\ \text { catheter } & 12 \mathrm{Fr} & 12\end{array}$

$\begin{array}{lll}\begin{array}{l}\text { Catheter } \\ \text { Type }\end{array} & \begin{array}{l}\text { Catheter } \\ \text { Size }\end{array} & \begin{array}{l}\text { Days to } \\ \text { Removal }\end{array} \\ \begin{array}{l}\text { Pigtail } \\ \text { catheter }\end{array} & 10 \mathrm{Fr} & 5 \\ \begin{array}{l}\text { Pigtail } \\ \text { catheter }\end{array} & 12 \mathrm{Fr} & 11 \\ \begin{array}{l}\text { Pigtail } \\ \text { catheter }\end{array} & 10 \mathrm{Fr} & 6\end{array}$

Catheter

Catheter

Days to 


\section{Cureus}

\begin{tabular}{|lllllll|} 
& (yrs) & & & Type & Size & Removal \\
14 & 30 & M & None & Straight drain $8 \mathrm{Fr}$ & 7 \\
15 & 32 & M & None & Straight drain $8 \mathrm{Fr}$ & 6 \\
\hline
\end{tabular}

\section{TABLE 1: Individual Patient Demographics, Diagnoses and Type of Catheters Used}

yrs = years, $F=$ female, $M=$ male, $F r=$ French, $D M=$ diabetes mellitus, HTN = hypertension, $C K D=$ chronic kidney disease

The mean number of days to catheter removal in all patients was $15 \pm 11.4$ days with a minimum of five days and a maximum number of 46 days. Of the seven patients with malignant pleural effusions, three (42.9\%) had a complete clinical resolution, three (42.9\%) had partial clinical resolution and one (14.2\%) had no clinical resolution. One patient (14.2\%) had a complete radiological resolution, two (28.6\%) had partial radiological resolution, and four (57.1\%) had no radiological resolution. Of the three patients with nonmalignant pleural effusion, two (66.7\%) had complete clinical resolution and one (33.3\%) had no clinical resolution, while two (66.7\%) had partial radiological resolution and one (33.3\%) had no radiological resolution. Of the three patients with empyema, all three had complete clinical resolution; but only partial radiological resolution was noted. Both (100\%) patients with PSP (primary spontaneous pneumothorax) had complete clinical, as well as, radiological resolution. Recurrence was noted in only two patients (13.3\%) who had a diagnosis of malignant pleural effusion making up $28.6 \%$ of the patients in that category. Another patient returned with complaints of shortness of breath, which was diagnosed as a malignant pleural effusion on the contralateral side.

One patient (6.7\%), comprising $14.2 \%$ of the malignant pleural effusion category, presented to the emergency room (ER) with complaints of no drain output and the problem was subsequently resolved. None of the patients required hospital admissions due to issues with the concerned procedure. One patient on hemodialysis from the nonmalignant pleural effusion category presented to the ER with hyperkalemia and was subsequently admitted for dialysis. The same patient (6.7\%) had a standard large-bore chest tube placed and surgery was done due to the failure of clinical and radiological resolution, even after 30 days.

In terms of complications, one patient (6.7\%) reported significant pain after the procedure. Another patient (6.7\%) had a displaced catheter, while a third patient (6.7\%) had kinking of the catheter. None of the patients' procedures were complicated with fever or pneumothorax.

When asked about the quality of life subsequently, one patient (6.7\%) reported a $40 \%$ limitation in his daily life activities, while the other 14 patients (93.3\%) did not report any decrease in their daily life activities.

Three patients with malignant pleural effusions expired after pleurodesis. The mean number of days to expiry after the procedure was $56 \pm 61.9$ days, with the minimum of 13 and maximum of 127 days. None of the deaths were due to complications related to the pleural pathologies being managed. Table 2 describes the outcomes for individual patients. 


\section{Cureus}

Malignant Pleural Effusions

Clinical Radiological

Resolution Resolution

$\begin{array}{lllll}\text { ER } & \text { Chest } & \text { Surgery } & \text { Complications Recurrence } & \begin{array}{l}\text { Expiry } \\ \text { (days) }\end{array}\end{array}$

None

0

No

No None

No

28

2 Complete

Complete

No

No None

No

3 Complete

Partial

No

No

None

Yes

4 None

None

No

No

None

No

5 Complete

None

No

No

None

No

13

6 Partial

Partial

No

No

None

No

$7 \quad$ Complete

None

No

No

None

Yes

Non-malignant Pleural Effusions

Clinical Radiologic

Resolution

Resolution

8 None

None

9 Complete

Partial

ER Chest

Visits

tube

Surgery Complications

Recurrence

10 Complete

Partial

1

Yes

Yes

Kinking

No

No

No

None

No

Empyema

Clinical Radiologic

ER

Visits

Chest

Resolution

Partial

0

tube

Surgery

Complications Recurrence

11 Complete

Partial

0

No

No

None

No

12 Complete

Partial

No

No

None

No

13 Complete

0

No

No

None

No

Primary Spontaneous Pneumothorax

Clinical

Resolution

Radiologic

Resolution

14 Complete

Complete

15 Complete

Complete
ER Chest

Visits tube

$0 \quad$ No

No

Decrease in

QoL

No

No No Pain

No

\section{TABLE 2: Outcome of Intervention for Individual Patients}

$\mathrm{ER}=$ emergency room, $\mathrm{QoL}=$ quality of life 


\section{Discussion}

We were able to manage several pleural pathologies requiring intervention on an outpatient basis with the help of small-bore indwelling catheters. Malignant pleural effusions, primary spontaneous pneumothorax, and empyema were the common causes seen in our case series. Patients tolerated these procedures well and were able to self-manage daily drainage of collection bag with some help from their family members. None of our patients were admitted, and the decisions about insertion and removal were taken and implemented on the outpatient basis.

Evidence of malignant pleural effusion (MPE) heralds stage- 4 cancers, regardless of the type. The median survival of patients with MPE is three months [13]. With palliative management, the success rate has been reported around $75 \%$ at one month and more than $50 \%$ by six months, along with the reported complications [16]. Among other goals of management, improving quality of life of the patients is of the utmost importance. Avoiding admission to the hospital, a decrease in hospital stays, and early removal of tubes are considered a constituent part of the quality of life. In the last couple of decades, these factors have been the focal points of clinicians in helping progress in the management of MPE.

In 1994, Villanueva, et al. compared short-term and long-term thoracoscopic drainage before pleurodesis and demonstrated that there was no significant difference in the outcomes [17]. Subsequent studies by Patz, et al. in 1996 [18], Hsu, et al. in 1998 [19] and Marom, et al. in 1999 [20] suggested the use of small-bore catheters for drainage and pleurodesis as a comparable alternative to previously used large-bore chest tubes.

In 2000, Saffran, et al. described outpatient pleurodesis in MPE using pigtail catheters [21]. The patients were not admitted after the insertion of the catheters contrary to common practice and further management was done on an ambulatory basis unless indicated otherwise. Six out of eight patients completing the procedure reported symptomatic improvement. In 2004, Musani, et al. reported complete or partially successful pleurodesis and symptomatic improvement in 11 (58\%) of 19 patients using a similar ambulatory procedure [15].

In 2003, Spiegler, et al. reported the use of rapid pleurodesis in which they did not wait for the drain output to decrease, and carried out pleurodesis within one to two days of the catheter tube insertion [22]. They reported complete response in 14 (48\%) of 27 patients and a partial response in nine (31\%) patients. Within the same study, two patients underwent ambulatory pleurodesis, only one of which had a partial response. While the ambulatory pleurodesis technique was similar to the one that we used, we did wait for the drain output to decrease to $100 \mathrm{cc}$ or less before we proceeded with pleurodesis.

In 2011, Bediwy and Amer described the use of an ambulatory technique for multiple pleural etiologies [10]. However, they described only short-term, i.e. within 72 hours of the removal of the pigtail catheter, success. Our study focused mainly on long-term success. With a success rate of $85.7 \%$ (42.9\% complete and $42.9 \%$ partial) of MPE, $66.7 \%$ of nonmalignant pleural effusions, $100 \%$ of empyema, and $100 \%$ of PSP and minimal complications, our study showed the effective use of this technique for various pleural pathologies with particular emphasis on MPE due to its tiring nature for both patients, as well as health care professionals.

Though radiological resolution was less successful in MPE (42.9\% (14.2\% complete and $28.6 \%$ partial)), palliation was our main focus, hence clinical resolution. In nonmalignant effusions, the radiological resolution (partial) was better at 66.7\%. Similarly, in empyema, the radiological resolution (partial) was $100 \%$ at the time of follow-up. This might be explained by the fact that it takes significantly more time in such patients for imaging to return to normal. Since the 
patients did not have any recurrence, imaging was not followed-up after the evidence of clinical resolution and improving radiology. In contrast, however, PSP, where the radiological improvement may be noted earlier, all the patients achieved complete radiological resolution.

The use of this technique is of particular importance, especially in developing countries similar to ours. In developed welfare states, the burden of health care is decreased with cost effective solutions such as the outpatient use of IPC. In resource constrained countries, such strategies help in reducing the financial burden on patients and their families, where the cost is mostly borne by them. A cost effective solution, such as this, would allow more patients in our setup to gain access to palliation in case of malignant pleural effusion, and definitive treatment in case of the curable pleural pathologies described.

The small sample size of a highly select population is a significant limitation in our study. Moreover, lack of direct comparison with conventional treatment modalities, i.e large-bore chest tubes, thoracoscopic decortication/pleurodesis, is another limitation. Previous studies indicate fever and pneumothorax to be the most reported complications after pleural catheter insertions. Patients in our study experienced neither of these. The use of ultrasound-guided catheter insertion might account for zero pneumothoraces in our cohort. The most significant complication in our study was pain (in $6.7 \%$ of the patients). This incidence was much lower than the reported $20-45 \%$ in some studies $[10,13,22]$.

Even though we did not include a formal cost analysis in our study, we expect that the cost will be much less in comparison to inpatient catheter insertions, avoiding hospital stays and surgical interventions requiring general anesthesia, operation theater services, and at times, thoracic surgical expertise.

\section{Conclusions}

Ambulatory, small-bore, pleural catheter insertion is a feasible management option in several pleural pathologies. It is easily tolerated, can be managed at home with an improved quality of life, and is potentially less costly in resource constrained environments. Further studies can be designed to include a wider population of patients with pathologies like secondary spontaneous pneumothorax, non-malignant effusions requiring pleurodesis, and complicated empyemas requiring fibrinolysis. It will also be of interest to study its use for palliation in patients with an expected survival time of fewer than six months in our population.

\section{Additional Information}

\section{Disclosures}

Human subjects: Consent was obtained by all participants in this study. Institutional Review Board \& Ethics Committee, Shifa International Hospital issued approval. Animal subjects: All authors have confirmed that this study did not involve animal subjects or tissue. Conflicts of interest: In compliance with the ICMJE uniform disclosure form, all authors declare the following: Payment/services info: All authors have declared that no financial support was received from any organization for the submitted work. Financial relationships: All authors have declared that they have no financial relationships at present or within the previous three years with any organizations that might have an interest in the submitted work. Other relationships: All authors have declared that there are no other relationships or activities that could appear to have influenced the submitted work.

\section{References}

1. Bobbio A, Dechartres A, Bouam S, et al.: Epidemiology of spontaneous pneumothorax: 
gender-related differences. Thorax. 2015, 70:653-658. 10.1136/thoraxjnl-2014-206577

2. MacDuff A, Arnold A, Harvey J: Management of spontaneous pneumothorax: British Thoracic Society pleural disease guideline 2010. Thorax. 2010, 65:18-31. 10.1136/thx.2010.136986

3. Parulekar W, Di Primio G, Matzinger F, et al.: Use of small-bore vs. large-bore chest tubes for treatment of malignant pleural effusions. Chest. 2001, 120:19-25. 10.1378/chest.120.1.19

4. Tsai WK, Chen W, Lee JC, et al.: Pigtail catheters vs large-bore chest tubes for management of secondary spontaneous pneumothoraces in adults. Am J Emerg Med. 2006, 24:795-800. 10.1016/j.ajem.2006.04.006

5. Patz EF, McAdams HP, Erasmus JJ, et al.: Sclerotherapy for malignant pleural effusions: a prospective randomized trial of bleomycin vs doxycycline with small-bore catheter drainage. Chest. 1998, 113:1305-1311. 10.1378/chest.113.5.1305

6. Lee YC, Fysh ET: Indwelling pleural catheter: changing the paradigm of malignant effusion management. J Thorac Oncol. 2011, 6:655-657. 10.1097/JTO.0b013e3182114aa0

7. VanMeter ME, McKee KY, Kohlwes RJ: Efficacy and safety of tunneled pleural catheters in adults with malignant pleural effusions: a systematic review. J Gen Intern Med. 2011, 26:7076. 10.1007/s11606-010-1472-0

8. Reddy C, Ernst A, Lamb C, Feller-Kopman D: Rapid pleurodesis for malignant pleural effusions: a pilot study. Chest. 2011, 139:1419-1423. 10.1378/chest.10-1868

9. Folch E, Santacruz JF: Rapid pleurodesis: an outpatient alternative . Chest. 2011, 140:16651666. 10.1378/chest.11-1681

10. Bediwy AS, Amer HG: Pigtail catheter use for draining pleural effusions of various etiologies . ISRN Pulmonology. 2012, (Epub ahead of print):10.5402/2012/143295

11. Humayon GM, Mushtaq MA, Ayyaz S et al.: Short term comparison of talc poudrage with tetracycline for medical pleurodesis in malignant pleural effusion. Pakistan Journal of Chest Medicine. 2012, 18:1-7.

12. Basit A, Khan MD, Ullah Z, et al.: The effectiveness of sustained (unclamped) pleurodesis in spontaneous pneumothorax. Pakistan J Chest Med. 2009, 15:13-17.

13. Putnam JB, Walsh GL, Swisher SG et al.: Outpatient management of malignant pleural effusion by a chronic indwelling pleural catheter. Ann Thorac Surg. 2000, 69:369-375.

10.1016/S0003-4975(99)01482-4

14. Aziz F, Penupolu S, Flores D: Efficacy of percutaneous pigtail catheters for thoracostomy at bedside. J Thorac Dis. 2012, 4:292-295. 10.3978/j.issn.2072-1439.2011.12.01

15. Musani AI, Haas AR, Seijo L, et al.: Outpatient management of malignant pleural effusions with small-bore, tunneled pleural catheters. Respiration. 2004, 71:559-566. $10.1159 / 000081755$

16. Fysh ET, Waterer GW, Kendall PA, et al.: Indwelling pleural catheters reduce inpatient days over pleurodesis for malignant pleural effusion. Chest. 2012, 142:394-400. 10.1378/chest.112657

17. Villanueva AG, Gray AW, Shahian DM, et al.: Efficacy of short term versus long term tube thoracostomy drainage before tetracycline pleurodesis in the treatment of malignant pleural effusions. Thorax. 1994, 49:23-25. 10.1136/thx.49.1.23

18. PatzJr EF, McAdams HP, Goodman PC, et al.: Ambulatory sclerotherapy for malignant pleural effusions. Radiology. 1996, 199:133-135. 10.1148/radiology.199.1.8633136

19. Hsu WH, Chiang CD, Chen CY, et al.: Ultrasound-guided small-bore Elecath tube insertion for the rapid sclerotherapy of malignant pleural effusion. Jpn J Clin Oncol. 1998, 28:187-191. 10.1093/jjco/28.3.187

20. Marom EM, PatzJr EF, Erasmus JJ, et al. : Malignant pleural effusions: treatment with smallbore-catheter thoracostomy and talc pleurodesis. Radiology. 1999, 210:277-281. 10.1148/radiology.210.1.r99dc04277

21. Saffran L, Ost DE, Fein AM, Schiff MJ: Outpatient pleurodesis of malignant pleural effusions using a small-bore pigtail catheter. Chest. 2000, 118:417-421. 10.1378/chest.118.2.417

22. Spiegler PA, Hurewitz AN, Groth ML: Rapid pleurodesis for malignant pleural effusions. Chest. 2003, 123:1895-1898. 10.1378/chest.123.6.1895 